\title{
Cation-Anionic Association of Organic Dyes in Aqueous Solutions: Structure and Properties of Associates
}

\author{
Serghey A. Shapovalov \\ Institute of Chemistry, V. N. Karazin Kharkiv National University, Ukraine \\ Email: serghey.a.shapovalov@karazin.ua
}

\begin{abstract}
Using the experimental and quantum chemical methods, the ionic association of dyes (cyanines, sulfonephthaleins) in aqueous solutions was systematically studied. The main regularities of association processes are revealed. The attention is focused on properties of cation-anionic associates of stoichiometric composition $\mathrm{Ct}^{+} \mathrm{HAn}^{-}$and $\left(\mathrm{Ct}^{+}\right)_{2} \mathrm{An}^{2-}$. The equilibrium association constants are spectrophotometrically determined. The enthalpies of formation of ions and associates were simulated by semiempirical AM1, PM3 methods. The most probable structures of associates are discussed.
\end{abstract}

Keywords: Dyes, cyanines, association, spectrophotometry, association constant, enthalpy of formation, cation-anionic associates, semiempirical methods, solution.

\section{Introduction}

It is known that the processes of association of various protolytic forms of organic dyes can significantly change the optical properties of the solution, primarily light absorption and (or) luminescence.

For dye molecules, F. Stenger observed more than a century ago changes of absorption and emission properties of dye solutions upon temperature variation and attributed such changes correctly to aggregation - disaggregation processes [1]. After the discovery of J-aggregation of dyes tremendous efforts have been devoted to the understanding of the structural and spectral properties of dye aggregates, and to explore the phenomenon for application in important technological areas such as photographic science. S. Sheppard revealed systematic changes in the absorption curves of cyanine dyes in various solvents and found substantial changes in UV/Vis spectra in solutions. Then G. Scheibe and E. E. Jelley in the 1930s found that absorption maxima are either shifted to shorter wavelengths (Haggregation) or sharply shifted to longer wavelengths (J-aggregation) relative to the absorption maximum of the molecular form with increasing concentration of dye solutions [2-6].

In the recent years, the application of dyes interaction is extended toward novel technological areas, including optical recording media [7], organic photo and semiconductors [8], solar cells [9-11], and chemical and biosensors [12-14]. In these fields, the term "functional dyes" has widely been used to emphasize on the new functionality beyond color of $\pi$-conjugated chromophores. In all of the abovementioned applications, functional dyes are assembled as one-dimensional stacks by aggregation of their $\pi$-systems through $\pi-\pi$ interactions $[15,16]$. In spite of it, the general structural, spectral and thermodynamic properties of associates should be discussed separately, and it will be done on. It should be noted that the solvent has a significant effect on the stability of non-covalent compounds, such as ionic associates. Therefore, a quantitative understanding of the features of associated systems remains to be the challenging tasks in the field of supramolecular organic chemistry.

Now, let us consider interactions and stable heteroassociates (i.e. "dissimilar" associates, further in the text associates) more in detail. Some facts of cation-anionic interactions with organic dyes were considered earlier [17]. In this report, on the basis on the results of spectrophotometric measurements and quantum chemical simulations, we have analysed the cation-anion interaction leading to the formation of stoichiometric associates between single-charged cations $\left(\mathrm{Ct}^{+}\right)$of quinaldine blue $\left(\mathrm{QB}^{+}\right)$or quinaldine red $\left(\mathrm{QR}^{+}\right)$and single- $\left(\mathrm{HAn}^{-}\right)$or two-charged $\left(\mathrm{An}^{2-}\right)$ sulfonephthalein anions. The energetics (standard enthalpy of formation, $\Delta H_{\mathrm{f}}^{\mathrm{f}}$ ) and the most probable structures of the associates " $\mathrm{Ct}^{+}+\mathrm{HAn}$ ", "Ct' $+\mathrm{An}^{2-"}$ are discussed also. Note that the $\mathrm{QB}^{+}$and $\mathrm{QR}^{+}$cations have proven themselves as «standard» organic dyes in studying of the association [18] due to its spectral and protolytic properties. 


\section{Experimental}

Dye preparations were used in the form of sodium or chloride salts ("Sigma"). The degree of purification of the dyes was checked from the well-known values of the molar absorption coefficient $\left(\varepsilon_{\max }, \mathrm{l} \cdot \mathrm{mol}^{-}\right.$ ${ }^{1} \cdot \mathrm{cm}^{-1}$ ) for the most colored protolytic forms. Phosphate, borate, acetate buffer solutions were used as additives to create the desired acidity. Additional experiments showed that these additives do not interfere with the studied association processes. The ionic strength of the photometric solutions was not more than $0.004 \mathrm{~mol} \cdot \mathrm{l}^{-1}$. The optical density $(A)$ values were in agreement with the basic law of light absorption when the equilibrium constants of association $\left(K_{\mathrm{as}}\right)$ were calculated. The light absorption of the solutions was measured at room temperature in all cases.

We have previously described examples of the application of quantum chemical methods for simulating the properties of individual ions of dyes and cation-anion associates [17-20]. A specific pH of the solution should be created to ensure the interaction of the cation $\mathrm{Ct}^{+}$with the anion $\mathrm{HAn}^{-}\left(\mathrm{or} \mathrm{An}^{2-}\right)$ of the corresponding dyes (the acidity of the solution should be such as to provide admixture of other protolytic forms). These conditions were chosen on the basis of the values $\mathrm{p} K_{\mathrm{a}}$ for each of the dyes.

Cations are protonated in acidic media, and form $\mathrm{CtOH}$ in alkaline media (see properties of cyanines in Table 1; values of $\mathrm{p} K_{\mathrm{a}}$ for $\mathrm{QR}$ and $\mathrm{QB}$ refer to the dissociation of the $\mathrm{HCt}^{2+}$ cation; for sulfonephthaleins the $\mathrm{p} K_{\mathrm{a} 2}$ values and the properties of $\mathrm{An}^{2-}$ are given). These processes cause partial bleaching of aqueous solutions of $\mathrm{QB}$ and QR because of the breakage of conjugation in the polymethine chain of the chromophore occurs.

Table 1. Characteristics of the dyes.

\begin{tabular}{|c|c|c|c|}
\hline \multirow{2}{*}{ Dye } & \multicolumn{3}{|c|}{ Parameter } \\
\hline & $\mathrm{p} K_{\mathrm{a}}$ & $\mathbf{\lambda}_{\max }, \mathbf{n m}$ & $\varepsilon_{\max }, \mathrm{l} \cdot \mathrm{mol}^{-1} \cdot \mathrm{cm}^{-1}$ \\
\hline QB & 3.50 & $\begin{array}{l}600, \alpha \text {-band } \\
550, \beta \text {-band } \\
510, \gamma \text {-band }\end{array}$ & $1.2 \cdot 10^{5}$ \\
\hline QR & 2.63 & 528 & $3.1 \cdot 10^{4}$ \\
\hline Phenolsulfonephthalein (PS) & 8.00 & 558 & $6.2 \cdot 10^{4}$ \\
\hline 3,3',5,5'-tetrabromophenolsulfonepthtalein (TBS) & 4.20 & 591 & $8.0 \cdot 10^{4}$ \\
\hline 3,3',5,5'-tetrabromophenol- $m$-cresolsulphophthaleine (TBC) & 4.90 & 617 & $4.0 \cdot 10^{4}$ \\
\hline 5,5'-dibromophenol-o-cresolsulphophthaleine (DCS) & 6.40 & 588 & $4.3 \cdot 10^{4}$ \\
\hline 3,3'-dibromothymolsulphophthaleine (DTS) & 7.30 & 616 & $4.13 \cdot 10^{4}$ \\
\hline
\end{tabular}

Thus, from a Table 1 it follows that for TBS it is reasonable to study the interaction of $\mathrm{Ct}^{+}$with $\mathrm{An}^{2}$ at $\mathrm{pH} \geq 6.2$.

For the correct calculation of the $K_{\text {as }}$ value according to the law of acting masses, it is necessary to use such values of dye concentrations that obey the basic law of light absorption $\mathrm{A}_{\lambda}=f(\mathrm{C})$. We have found that $\mathrm{QR}^{+}$and sulfonephthaleins obey this law over a broad range of concentrations (from $3 \cdot 10^{-7}$ up to $\left.5 \cdot 10^{-4} \mathrm{M}\right)$.

The values of free regression term are statistically zero, and we assumed $A_{\lambda}=\mathrm{k} \cdot \mathrm{C}$. It is worth noting the practical coincidence of correlation coefficient with the unity. This gives reason to suggest that sulfonephthalein anions and $\mathrm{QR}^{+}$do not dimerize in the studied concentration intervals. For $\mathrm{QB}^{+}$, in contrast, the main law of the light absorption operates only at low concentrations $\left(3 \cdot 10^{-7}\right.$ to $\left.1 \cdot 10^{-6} \mathrm{M}\right)$, since this organic dye is subjected to self-association. The dimerization of $\mathrm{QB}^{+}$appears spectrally in a 
sharp weakening of the absorption of the $\alpha$-band and rise in the intensity of the $\beta$-band (see Table 1 ).

\section{Results and Discussion}

\subsection{Association Constant Study}

Cation-anionic associates are formed in an aqueous solution if certain amounts of cyanine and sulfonephthalein are mixed. A characteristic sign of the appearance of the associate can be identified by analyzing the spectral changes. The measured light absorption of mixtures (" $\mathrm{Ct}^{+}+\mathrm{HAn}^{-}$", " $\mathrm{Ct}^{+}+\mathrm{An}^{2-}$ ") is lower than the total absorption of the "isolated" cation $\left(\mathrm{Ct}^{+}\right)$and anion $\left(\mathrm{HAn}^{-}\right.$or $\left.\mathrm{An}^{2-}\right)$. This nonadditivity of light absorption is observed in all the cases under consideration. This takes place even at different molar concentrations of counterions. For example, nonadditivity of light absorption is detected for the system "QB + DCS" both at QB concentration $4.9 \cdot 10^{-7} \mathrm{M}$ (Figure 1, "Ct $\mathrm{Ct}^{+}+\mathrm{HAn}^{-}$" system) and at much higher concentration $4.9 \cdot 10^{-5} \mathrm{M}$ (Figure 2 , "Ct+ $\mathrm{Ct}^{+} \mathrm{An}^{2-"}$ system). We also note that the proper light absorption of the dye QB (spectrum 1) in Figure 2 differs from that in Figure 1 (spectrum 1). This is due to a noticeable manifestation of the process of dimerization of the cyanine dye with increasing molar concentration. The intensity of the $\alpha$-band is higher in Figure 1, and the intensity of the $\beta$-band is higher in Figure 2 (also see properties for QB in Table 1).

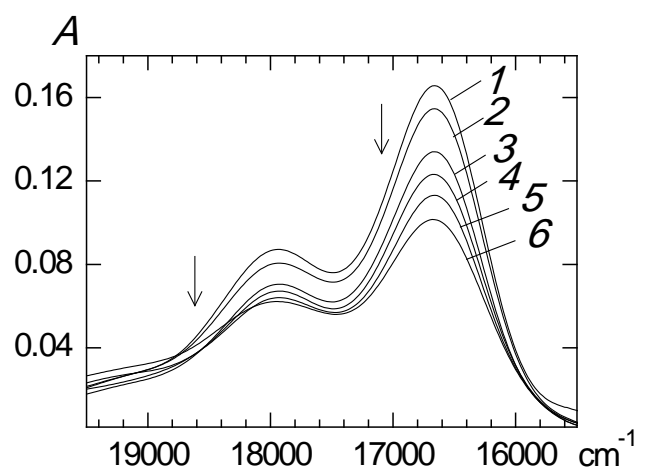

Figure 1. Absorbtion spectra of QB solution $\left(4.9 \cdot 10^{-7} \mathrm{M}\right)$ vs. the DCS concentration, M: 0 (1), $1.0 \cdot 10^{-6}$ (2), $3.5 \cdot 10^{-6}(3), 5.0 \cdot 10^{-6}(4), 9.9 \cdot 10^{-6}(5), 1.5 \cdot 10^{-5}(6)$. The optical path length is $5.0 \mathrm{~cm}$. pH 4.3 . Here and in Figure 2 water $(1)$ and a DCS solution in the corresponding concentration $(2-6)$ were as blank solutions. The arrows indicate the spectral shifts here and in Figure 2 also.

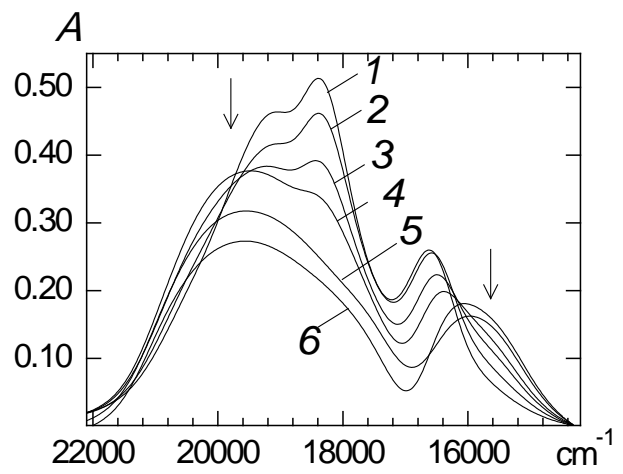

Figure 2. Absorbtion spectra of QB solution $\left(4.9 \cdot 10^{-5} \mathrm{M}\right)$ vs. the DCS concentration, M: 0 (1), $5.1 \cdot 10^{-6}$ (2), $1.5 \cdot 10^{-5}(3), 2.0 \cdot 10^{-5}(4), 3.0 \cdot 10^{-5}(5), 5.0 \cdot 10^{-5}(6)$. Optical path length is $0.20 \mathrm{~cm} . \mathrm{pH} 9.2$.

At specific initial concentrations of counterions and their molar ratio, sulfonephthalein anions form stoichiometric $\mathrm{Ct}^{+} \cdot \mathrm{HAn}^{-}$and $\left(\mathrm{Ct}^{+}\right)_{2} \cdot \mathrm{An}^{2-}$ associates. The association of such ions is an equilibrium process [18]. Therefore, the stability of an associate is characterized by the value of the equilibrium 
constant $K_{\mathrm{as}}$. It can be determined using the law of mass action for such equilibria:

$$
\begin{aligned}
& \mathrm{Ct}^{+}+\mathrm{HAn}^{-} \rightleftarrows \mathrm{Ct}^{+} \cdot \mathrm{HAn}^{-}, \\
& 2 \mathrm{Ct}^{+}+\mathrm{An}^{2-} \rightleftarrows\left(\mathrm{Ct}^{+}\right)_{2} \cdot \mathrm{An}^{2-} .
\end{aligned}
$$

The values of $K_{\text {as }}$ are:

$$
K_{\mathrm{as}}=\left[\mathrm{Ct}^{+} \cdot \mathrm{HAn}^{-}\right] \cdot\left[\mathrm{Ct}^{+}\right]^{-1} \cdot\left[\mathrm{HAn}^{-}\right]^{-1}
$$

and:

$$
K_{\mathrm{as}}=\left[\left(\mathrm{Ct}^{+}\right)_{2} \cdot \mathrm{An}^{2-}\right] \cdot\left[\mathrm{Ct}^{+}\right]^{-2} \cdot\left[\mathrm{An}^{2-}\right]^{-1}
$$

(there are the spectrophotometrically determined equilibrium molar concentrations of the corresponding particles in brackets). The values of $\lg K_{\text {as }}$ are listed in Table 2.

The Kas values practically do not differ from thermodynamic ones, since the dye concentrations are very low and the ionic strength of the solutions is $\leqslant 0.004 \mathrm{~mol} \cdot \mathrm{l}^{-1}$.

Table 2. The values of $\lg K_{\text {as }}$ of associates.

\begin{tabular}{c|cc}
\hline \multirow{2}{*}{ Anion } & \multicolumn{2}{|c}{$\lg \boldsymbol{K}_{\mathrm{as}}\left(\mathrm{QB}^{+}\right.$associate $/ \mathrm{QR}^{+}$associate $)$} \\
\cline { 2 - 3 } & $\mathbf{C t}^{+} \cdot \mathbf{H A n}$ & $\left(\mathbf{C t}^{+}\right)_{2} \cdot \mathbf{A n}^{2-}$ \\
\hline PS & $5.83 \pm 0.10 / 5.13 \pm 0.09$ & $11.81 \pm 0.10 / 8.64 \pm 0.09$ \\
DTS & $5.95 \pm 0.11 / 4.45 \pm 0.08$ & $10.89 \pm 0.09 / 7.85 \pm 0.09$ \\
DCS & $6.67 \pm 0.05 / 4.78 \pm 0.06$ & $11.07 \pm 0.10 / 8.23 \pm 0.04$ \\
TBC & $6.74 \pm 0.04 / 5.04 \pm 0.07$ & $12.09 \pm 0.09 / 8.64 \pm 0.07$ \\
TBS & $6.88 \pm 0.05 / 5.27 \pm 0.05$ & $13.73 \pm 0.10 / 8.86 \pm 0.08$ \\
\hline
\end{tabular}

As follows from the data in the Table 2, the Kas values are statistically different. First of all, QB associates are systematically more stable than QR associates. Secondly, the alkyl substituents in the structure of sulfonephthalein may hinder the convergence of the planar $\pi$-electron systems and thereby weaken the interaction of the counterions. In contrast, the halogen atoms do not distort planarity. In addition, they enhance the hydrophobic component of intermolecular interactions, which facilitates the interaction of cations with single or double-charged anions.

The value of $K_{\mathrm{as}}$ increases for quinaldine blue associates in the series:

$$
\begin{aligned}
& \mathrm{DTS}^{-}<\mathrm{DCS}^{-} \approx \mathrm{TBC}^{-}<\mathrm{TBS}^{-}, \\
& \mathrm{DTS}^{2-} \approx \mathrm{DCS}^{2-}<\mathrm{TBC}^{2-}<\mathrm{TBS}^{2-},
\end{aligned}
$$

and for quinaldine red associates in the series:

$$
\begin{aligned}
& \mathrm{DTS}^{-}<\mathrm{DCS}^{-}<\mathrm{TBC}^{-}<\mathrm{TBS}^{-} \\
& \mathrm{DTS}^{2-}<\mathrm{DCS}^{2-}<\mathrm{TBC}^{2-}<\mathrm{TBS}^{2-} .
\end{aligned}
$$

As follows from Table 2, TBS anions form the most stable associates, since, on the one hand, they do not have alkyl substituents, and on the other they have four bromine atoms. The presence of alkyl substituents reduces stability (associates of TBC). Associates of DCS or DTS, containing two bromine atoms and alkyl substituents, are even less stable. Stability of PS2- associates is greater than DTS associates and less than TBS associates for these reasons.

The presence of a developed $\pi$-electron system is an important factor in the association of organic molecules, along with Coulomb forces. It enhances dispersion interactions between chromophores, especially for flattened structures like cyanines, squaraines, porphyrins, xanthenes, spiropyrans [6, 18, 21-23]. It is known that such molecules easily form H- or J-aggregates and even multilayer thin films. However, the sulfonephthalein anions are not flat. They are like a propeller and are not inclined to aggregate at low concentrations. Nevertheless, these anions form stoichiometric associates when interacting with cyanines. Therefore, it is reasonable to define energetics and the most probable structure of stoichiometric associates by quantum chemical simulations and then compare their energetic parameters (first of all, the standard enthalpies of formation, $\Delta H_{\mathrm{f}}^{\circ}$ ). 


\subsection{The Structure and Energy of Associates}

In some cases, nonempirical methods have been successfully used to evaluate energy $\left(\Delta H_{\mathrm{f}}^{\circ}\right)$ of small organic molecules. The calculation error does not exceed $100 \mathrm{~kJ} \cdot \mathrm{mol}^{-1}$ when ab initio method is used [24]. However, the error increases dramatically with increasing number of atoms. It can be much greater for supramolecular systems such as cation-anionic associates, as a result of ignoring the correlation energy of electrons. We used semi-empirical AM1 and PM3 methods in order to reduce the error of calculation of $\Delta H_{\mathrm{f}}^{\circ}$ value to about $25 \mathrm{~kJ} \cdot \mathrm{mol}^{-1}[24,25]$. These methods are applied to organic molecules and parameterized in such a way to best reproduce the experimental values of enthalpy.

The use of two methods of calculation is related not only to the tendency to assess the higher reliability in absolute values of $\Delta H_{\mathrm{f}}^{\circ}$, but also to minimize the systematic error in the discovery of the change in for associates of similar composition. The $\Delta H_{\mathrm{f}}^{\circ}$ values for ions of the dyes are given in Table 3 ("MOPAC-2009" program [26]).

Table 3 The values of $\Delta H_{\mathrm{f}}^{\circ}$ of organic ions.

\begin{tabular}{|c|c|c|}
\hline \multirow{2}{*}{ Ion } & \multicolumn{2}{|c|}{$\Delta H_{\mathrm{f}}^{\circ}, \mathrm{kJ} \cdot \mathrm{mol}^{-1}$} \\
\hline & AM1 & PM3 \\
\hline $\mathrm{QB}^{+}$ & $1076.8 \ldots 1073.5$ & $980.8 \ldots 968.7$ \\
\hline $\mathrm{QR}^{+}$ & $989.3 \ldots 984.2$ & $918.8 \ldots 912.6$ \\
\hline $\mathrm{PS}^{-} / \mathrm{PS}^{2-}$ & $-556.0 \ldots-576.5 /-479.3 \ldots-492.7$ & $-575.7 \ldots-586.2 /-534.2 \ldots-536.7$ \\
\hline $\mathrm{TBS}^{-} / \mathrm{TBS}^{2-}$ & $-465.8 \ldots-479.6 /-473.1 \ldots-474.3$ & $-435.8 \ldots-460.9 /-450.0 \ldots-451.7$ \\
\hline $\mathrm{TBC}^{-} / \mathrm{TBC}^{2-}$ & $-471.8 \ldots-481.4 /-476.8 \ldots-478.5$ & $-469.3 \ldots-478.1 /-469.3 \ldots-472.6$ \\
\hline $\mathrm{DCS}^{-} / \mathrm{DCS}^{2-}$ & $-583.7 \ldots-602.1 /-554.8 \ldots-556.9$ & $-584.5 \ldots-609.6 /-566.5 \ldots-570.3$ \\
\hline $\mathrm{DTS}^{-} / \mathrm{DTS}^{2-}$ & $-662.4 \ldots-681.7 /-634.8 \ldots-639.8$ & $-685.5 \ldots-691.4 /-658.3 \ldots-666.6$ \\
\hline
\end{tabular}

The process of geometric optimization of the structure is characterized by a gradual decrease in the RMS value during the simulation. Note, that RMS gradient is the rate of the energy change (first derivative) upon changes in the position of every atom in three mutually perpendicular directions (the local energy minimum is achieved when it becomes equal to zero) [24]. The RMS value was decreased from 4.2 to $0.04 \mathrm{~kJ} \cdot \mathrm{mol}^{-1} \cdot \AA^{-1}$ for two consecutive iterations in our cases. This allowed us to determine the $\Delta H_{\mathrm{f}}^{\circ}$ value with a range of variation of not more than $25.1 \mathrm{~kJ} \cdot \mathrm{mol}^{-1}$ (TBS- or DCS-, for PM3 method), and $13.4 \mathrm{~kJ} \cdot \mathrm{mol}^{-1}\left(\mathrm{PS}^{2-}\right.$, for AM1 method). As we see, both semiempirical methods have a rather small error in calculating the $\Delta H_{\mathrm{f}}^{\circ}$ value of ions (the maximum error is $5.4 \%$ (TBS-) for AM1 method and $2.7 \%\left(\mathrm{PS}^{2-}\right)$ for PM3 method). Despite some numerical differences, the results of AM1 and PM3 calculations do not contradict each other. The maximum difference $\left(44 \mathrm{~kJ} \cdot \mathrm{mol}^{-1}\right)$ is obtained for the $\mathrm{PS}^{2-}$ anion. It indicates a completely satisfactory agreement of the results. The most negative $\Delta H_{\mathrm{f}}^{\circ}$ data were chosen as final values.

From the set of obtained simulated values of $\Delta H_{\mathrm{f}}^{\circ}$ you should choose one that corresponds to the lowest value of energy. This is so-called "global minimum energy" of an associate. We determined it based on various (usually 6-7) of the starting positions of the counterions in the associate (the geometry of each ion was preliminarily optimized in the same way). At the same time, the optimization progress was monitored by the values of the RMS gradient from 0.1 to $5 \cdot 10^{-3}-1 \cdot 10^{-4} \mathrm{~kJ} \cdot \mathrm{mol}^{-1} \cdot \AA^{-1}$. Termination of the optimization was determined by the absence of change in from the RMS values. This often occurred at from $5 \cdot 10^{-2}$ to $5 \cdot 10^{-3} \mathrm{~kJ} \cdot \mathrm{mol}^{-1} \cdot \AA^{-1}$ for cations and at slightly lower values for sulfonephthaleins. As an example, the dependences of the value $\Delta H_{\mathrm{f}}^{\circ}$ on the RMS gradient for DTS associates are shown in Figure 3. 


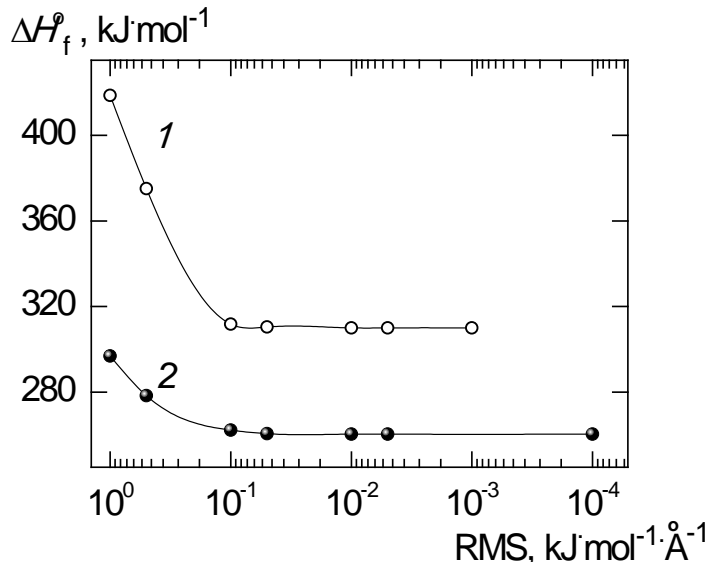

Figure 3. Change in $\Delta H_{\mathrm{f}}^{\circ}$ depending on the given values of the RMS gradient: 1 - is the associate of $\mathrm{QB}^{+}$with $\mathrm{DTS}^{2-}$ anion; 2 - is the associate of $\mathrm{QB}^{+}$with the $\mathrm{DTS}^{-}$anion.

The mutual arrangement of dyes varies and the distance between them are gradually decreased at RMS values from 1 to $0.1 \mathrm{~kJ} \cdot \mathrm{mol}^{-1} \cdot \AA^{-1}$. The further decrease of RMS does not change both the mutual disposition of the counterions, and the $\Delta H_{\mathrm{f}}^{\circ}$ values (see Figure 3 ).

The optimized geometric structure of the associate $\mathrm{QB}^{+} \cdot \mathrm{DTS}^{-}$is shown in Figure 4 (the stereo views are given for clarity; the hydrogen atoms in dye ions are not shown; the distance between the selected atoms is $5,5 \AA$ ).
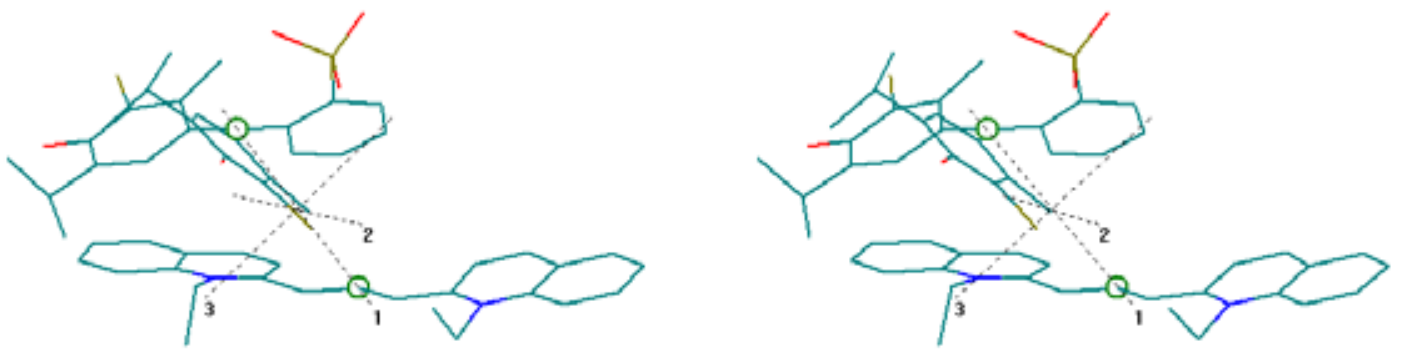

Figure 4. Geometric structure of the associate $\mathrm{QB}^{+} \cdot \mathrm{DTS}^{-}$(stereo imagine).

The characteristics of dye ions and DTS associates are shown in Figures 5 and 6 as examples.

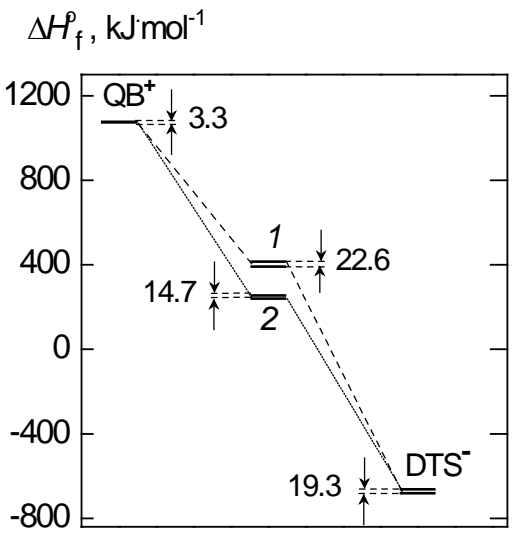

Figure 5. The values of $\Delta H_{\mathrm{f}}^{\circ}$ of $\mathrm{QB}^{+}$and $\mathrm{DTS}^{-}$ions, and the algebraic sum of $\Delta H_{\mathrm{f}}^{\circ}$ of ions composing the associate (1) and $\Delta H_{\mathrm{f}}^{\circ}$ of the associate $\mathrm{QB}^{+} \cdot \mathrm{DTS}^{-}$(2), AM1 method. Digits nearby the arrows specify the scope of variations in $\Delta H_{\mathrm{f}}^{\circ}$ values of the species here and Figure 6. 


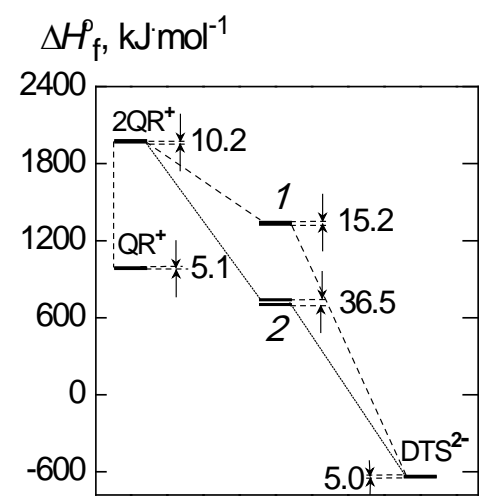

Figure 6. The values of $\Delta H_{\mathrm{f}}^{\circ}$ of $\mathrm{QR}^{+}$and $\mathrm{DTS}^{2-}$ ions, and the algebraic sum of $\Delta H_{\mathrm{f}}^{\circ}$ of ions composing the associate (1) and $\Delta H_{\mathrm{f}}^{\circ}$ of the associate $\left(\mathrm{QR}^{+}\right)_{2} \cdot \mathrm{DTS}^{2-}$ (2), AM1 method.

In Figure 5 the QB+ and DTS- ions are characterized by $\Delta H_{\mathrm{f}}^{\circ} 1076.8 \ldots 1073.5$ and -662.4 to $-681.7 \mathrm{~kJ}$. $\mathrm{mol}^{-1}$, respectively. Their algebraic sum $\left(414.4 \ldots 391.8 \mathrm{~kJ} \cdot \mathrm{mol}^{-1}\right.$, energy level 1) is larger than $\Delta H_{\mathrm{f}}^{\circ}$ of the associate $\left(255.2 \ldots 240.5 \mathrm{~kJ} \cdot \mathrm{mol}^{-1}\right.$, level 2) by $173.9 \ldots 136.6 \mathrm{~kJ} \cdot \mathrm{mol}^{-1}$. Similarly, in Figure 6 the QR + and DTS2 - ions are characterized by $\Delta H_{\mathrm{f}}^{\circ} 989.3 \ldots 984.2 \mathrm{~kJ} \cdot \mathrm{mol}^{-1}$ and $-634.8 \ldots-639.8 \mathrm{~kJ} \cdot \mathrm{mol}^{-1}$, whereas two cations QR + have the energy of $1978.6 \ldots 1968.4 \mathrm{~kJ} \cdot \mathrm{mol}^{-1}$. The algebraic sum of $\Delta H_{\mathrm{f}}^{\circ}$ of counter ions is $1343.8 \ldots 1328.6 \mathrm{~kJ} \cdot \mathrm{mol}^{-1}$ (level 1). Since $\Delta H_{\mathrm{f}}^{\circ}$ of the associate was found to be equal to $740.0 \ldots 703.5 \mathrm{~kJ}$. $\mathrm{mol}^{-1}$ (level 2), the surplus of the algebraic sum of $\Delta H_{\mathrm{f}}^{\circ}$ of counter ions over $\Delta H_{\mathrm{f}}^{\circ}$ of the associate is $640.3 \ldots 588.6 \mathrm{~kJ} \cdot \mathrm{mol}^{-1}$.

Table 4. The energy properties of associates (AM1/PM3).

\begin{tabular}{|c|c|c|c|}
\hline Dye & $\Sigma, \mathrm{kJ} \cdot \mathrm{mol}^{-1}$ & $\Delta H_{\mathrm{f}}^{\circ}, \mathrm{kJ} \cdot \mathrm{mol}^{-1}$ & $\delta, \%$ \\
\hline \multicolumn{4}{|c|}{$\mathrm{QR}^{+} \cdot \mathrm{HAn}^{-}$} \\
\hline PS & $407 / 326$ & $258 / 122$ & $16 / 8$ \\
\hline TBS & $504 / 451$ & $339 / 267$ & $14 / 34$ \\
\hline $\mathrm{TBC}$ & $502 / 434$ & $331 / 241$ & $13 / 9$ \\
\hline DCS & $382 / 303$ & $219 / 107$ & $13 / 14$ \\
\hline DTS & $303 / 221$ & $147 / 81$ & $14 / 7$ \\
\hline \multicolumn{4}{|c|}{$\left(\mathrm{QR}^{+}\right)_{2} \cdot \mathrm{An}^{2-}$} \\
\hline PS & $1475 / 1288$ & $757 / 518$ & $5 / 4$ \\
\hline TBS & $1494 / 1373$ & $839 / 547$ & $9 / 3$ \\
\hline TBC & $1489 / 1352$ & $853 / 628$ & $13 / 7$ \\
\hline DCS & $1411 / 1254$ & $737 / 525$ & $7 / 7$ \\
\hline DTS & $1328 / 1158$ & $703 / 406$ & $8 / 12$ \\
\hline \multicolumn{4}{|c|}{$\mathrm{QB}^{+} \cdot \mathrm{HAn}^{-}$} \\
\hline PS & $497 / 382$ & $344 / 134$ & $19 / 9$ \\
\hline TBS & $593 / 507$ & $423 / 347$ & $19 / 21$ \\
\hline $\mathrm{TBC}$ & $592 / 490$ & $432 / 328$ & $19 / 14$ \\
\hline DCS & $471 / 359$ & $312 / 202$ & $29 / 28$ \\
\hline DTS & $391 / 277$ & $240 / 105$ & $21 / 12$ \\
\hline \multicolumn{4}{|c|}{$\left(\mathrm{QB}^{+}\right)_{2} \cdot \mathrm{An}^{2-}$} \\
\hline PS & $1654 / 1400$ & $979 / 788$ & $6 / 7$ \\
\hline TBS & $1672 / 1485$ & $1011 / 824$ & $3 / 8$ \\
\hline $\mathrm{TBC}$ & $1668 / 1464$ & $1060 / 817$ & $3 / 6$ \\
\hline DCS & $1590 / 1367$ & $928 / 703$ & $4 / 6$ \\
\hline DTS & $1507 / 1270$ & $858 / 527$ & $6 / 8$ \\
\hline
\end{tabular}


We calculated $\Delta H_{\mathrm{f}}^{\circ}$ values for all of the studied associates. The algebraic sum $(\Sigma)$ of the $\Delta H_{\mathrm{f}}^{\circ}$ values of corresponding ions in associates (the first column) determined as $\Sigma=i \cdot \Delta H_{\mathrm{f}}^{\circ}(\mathrm{Ct})+\Delta H_{\mathrm{f}}^{\circ}(\mathrm{An})$, where $i$ is the number of cations in the associate (the second column), and the relative errors $(\delta, \%)$ of $\Sigma-\Delta H_{\mathrm{f}}^{\circ}$ calculation (the fourth column), are presented in Table 4 (rounded values).

A number of important conclusions can be drawn based on the analysis of the data in Table 4 and the obtained results. Since the error in the calculated $\Sigma-\Delta H_{\mathrm{f}}^{\circ}$ value is not higher than the above mentioned average error of the method in the calculation of the values of $\Delta H_{\mathrm{f}}^{\circ}$ one can assert that the formation of all associates is energetically favorable, especially in the case of association of sulfonephthaleins with the structures containing developed $\pi$-electronic systems $\left(\mathrm{QB}^{+}\right)$; the gain in the energy is approximately $150-160 \mathrm{~kJ} \cdot \mathrm{mol}^{-1}$ (associates of $\mathrm{HAn}^{-}$, see also Figure 5) and $605-$ $700 \mathrm{~kJ} \cdot \mathrm{mol}^{-1}$ (associates of $\mathrm{An}^{2-}$, see also Figure 6).

The changes in $\Delta H_{\mathrm{f}}^{\circ}$ (vacuum) and Kas (aqueous solution) should not necessarily be in agreement. Besides, the semiempirical calculations cannot take into account some specific interactions (e.i., hydrophobic interactions intrinsic to the bulky polyatomic ions of dyes). Nevertheless, the calculations revealed almost the same sequence of changes in $\Delta H_{\mathrm{f}}^{\circ}$ values, as for the experimental values of Kas. Thus, for HAn- the values of $\Delta H_{\mathrm{f}}^{\circ}$ increase in the series (values of $\Delta H_{\mathrm{f}}^{\circ}, \mathrm{kJ} \cdot \mathrm{mol}^{-1}, \mathrm{PM} 3 \mathrm{method}$ ):

$$
\begin{gathered}
\mathrm{QB}^{+} \cdot \mathrm{DTS}^{-}(105)<\mathrm{QB}^{+} \cdot \mathrm{DCS}^{-}(202)<\mathrm{QB}^{+} \cdot \mathrm{TBC}^{-}(328)<\mathrm{QB}^{+} \cdot \mathrm{TBS}^{-}(347), \\
\mathrm{QR}^{+} \cdot \mathrm{DTS}^{-}(81)<\mathrm{QR}^{+} \cdot \mathrm{DCS}^{-}(107)<\mathrm{QR}^{+} \cdot \mathrm{TBC}^{-}(241)<\mathrm{QR}^{+} \cdot \mathrm{TBS}^{-}(267),
\end{gathered}
$$

and, analogically, for An2- in the series (and both methods):

$$
\mathrm{DTS}^{2-}<\mathrm{DCS}^{2-}<\mathrm{TBS}^{2-} \approx \mathrm{TBC}^{2-} \text {. }
$$

As in the case of Kas, the values of $\Delta \mathrm{H}^{\circ} \mathrm{f}$ of $\mathrm{PS}$ associates have the intermediate values:

$$
\text { DTS }<\text { PS }<\text { TBS }
$$

regardless of the composition. These unobvious facts support the assumption that the bromine atoms in the structure of sulfonephthalein favor interactions with cationic dyes.

Hence, the values of Kas and $\Delta H_{\mathrm{f}}^{\circ}$ in the series of the structurally similar associates change in parallel.

\section{Conclusion}

The revealed differences in the values of $K_{\mathrm{as}}$ or $\Delta H_{\mathrm{f}}^{\circ}$ are of a regular nature even in a set of structurally uniform associates. Systematic study of the cation-anionic interactions makes it clear that the association processes of organic particles are accompanied by a rather complex combination of Coulomb forces (hydrophobic; dispersion; and, in part, $\pi$-electron interactions) whose further study requires the results from spectral measurements to be compared against the data of computer simulations.

The obtained data on association confirm the necessity of search of correlations between structural features of organic molecules and properties of supramolecular associates.

\section{Acknowledgments}

The author is thankful to Dr. Ya. A. Svishchova, V.V. Dokuchaev's Kharkiv National Agrarian University, for carrying out a number of spectral measurements.

\section{References}

1. Fr. Stenger, "Ueber die Gesetzmässigkeiten im Absorptionsspectrum eines Körpers," Ann. Phys. Chem., Bd. 33, no 4 , S. $577-586,1888$.

2. E. Jelley, "Spectral Absorption and Fluorescence of Dyes in the Molecular State," Nature, vol. 138, pp. 1009-1010, 1936.

3. E. Jelley, "Molecular, Nematic and Crystal States of I: I-Diethyl-Cyanine Chloride," Nature, vol. 139, pp. 631631, 1937.

4. G. Scheibe "Über die Veränderlichkeit der Absorptionsspektren in Lösungen und die Nebenvalenzen als ihre Ursache," Angewandte Chemie, vol. 50, pp. 212-219, 1937.

5. F. Würthner, T. E. Kaiser and C. R. Saha-Möller, "J-Aggregates: From Serendipitous Discovery to 
Supramolecular Engineering of Functional Dye Materials," Angewandte Chemie Internat. Edition, vol. 50, pp. 3376-3410, 2011.

6. B. I. Shapiro, "Aggregates of Cyanine Dyes: Photographic Problems", Russian Chemical Review, vol. 63, pp. 231-255, 1994.

7. H. Mustroph, M. Stollenwerk and V. Bressau, "Current Developments in Optical Data Storage with Organic Dyes," Angewandte Chemie Internat. Edition, vol. 45, pp. 2016-2035, 2006.

8. F. C. Grozema and L. D. A. Siebbeles, "Mechanism of Charge Transport in Self-organizing Organic Materials," International Reviews in Physical Chemistry, vol. 27, pp. 87-138, 2008.

9. L. SchmidtMende, A. Fechtenkötter, K. Müllen, E. Moons, R. H. Friend and J. D. MacKenzie, "SelfOrganized Discotic Liquid Crystals for High-efficiency Organic Photovoltaics," Science, vol. 293, pp. 1119-1122, 2001.

10. Chih-Jen Yang, Yuan Jay Chang, Motonori Watanabe, Yung-Son Hona and Tahsin J. Chow, "Phenothiazine Derivatives as Organic Sensitizers for Highly Efficient Dye-sensitized Solar Cells," Journal of Materials Chemistry, vol. 22, pp. 4040-4049, 2012.

11. Ming-Dao Zhang, Hao Pan, Xue-Hai Ju, Ya-Jun Ji, Ling Qin, He-Gen Zheng and Xing-Fu Zhou, "Improvement of Dye-sensitized Solar Cells' Performance through Introducing Suitable heterocyclic Groups to Triarylamine Dyes," Physical Chemistry Chemical Physics, vol. 14, pp. 2809-2815, 2012.

12. Ha Na Kim, Min Hee Lee, Hyun Jung Kim, Jong Seung Kim and Juyoung Yoon, "A New Trend in Rhodaminebased Chemosensors: Application of Spirolactam Ring-opening to Sensing Ions," Chemical Society Reviews, vol. 37, pp. 1465-1472, 2008.

13. Y. Zhou and J. Yoon, "Recent Progress in Fluorescent and Colorimetric Chemosensors for Detection of Amino Acids," Chemical Society Reviews, vol. 41, pp. 52-67, 2012.

14. V. L. Malinovskii, D. Wenger and R. Häner, "Nucleic Acid guided Assembly of Aromatic Chromophores," Chemical Society Reviews. vol. 39, pp. 410-422, 2010.

15. E. Masson, X. Ling, R. Joseph, L. Kyeremeh-Mensaha and X. Lua, "Cucurbituril Chemistry: a Tale of Supramolecular Success," RSC Advances, vol. 2, pp. 1213-1247, 2012.

16. J. G. Hill and J. A. Platts, "Local Electron Correlation Descriptions of the Intermolecular Stacking Interactions Between Aromatic Intercalators and Nucleic Acids," Chemical Physics Letters, vol. 479, pp. 279-283, 2009.

17. S. A. Shapovalov, V. L. Koval, T. A. Chernaya, A. Yu. Pereverzev, N. A. Derevyanko, A. A. Ishchenko and N. O. Mchedlov-Petrossyan, "Association of Indopolycarbocyanine Cations with Anions of Sulfphonephthalein and Xanthene dyes," Journal of the Brazilian Chemical Society, vol. 16, pp. 232-240, 2005.

18. A.A. Ishchenko and S.A. Shapovalov, "Heterogeneous association of the ions of dyes in solutions (review)," Journal of Applied Spectroscopy, vol. 71, pp. 605-629, 2004.

19. S. A. Shapovalov, E. A. Samoilov and V. V. Ivanov, "On the agreement of the results of semiempirical quantum chemical calculations of the structural properties of dyes and their ionic associates," (in Russ.) Proceedings of Higher Educational Institutions. Chemistry and Chemical Technology (Russia), vol. 49, pp. 39-44, 2005.

20. S. A. Shapovalov and E. A. Samoilov, "Regularities of Homo- and Heteroassociation of the Pinacyanol Cation in Aqueous Solution," Russian Chemical Bulletin, Internat. Edition, vol. 57, pp. 1405-1415, 2008.

21. B. I. Shapiro, "Molecular Assemblies of Polymethine Dyes," Russian Chemical Review, vol. 75, pp. 433-456, 2006.

22. J. J. McEwen and K. J. Wallace, "Squaraine Dyes in Molecular Recognition and Self-assembly," Chemical Communications, vol. 42, pp. 6339-6351, 2009.

23. F. Würthner, T. E. Kaiser and C. R. Saha-Möller, "J-aggregates: from Serendipitous Discovery to Supramolecular Engineering of Functional Materials," Angewandte Chemie Internat. Edition, vol. 50, pp. 33763410, 2011.

24. S. A. Astakhov, V. I. Baranov and L. A. Gribov, Theory and methods of computational vibronic spectroscopy. New York, Nova Science Publishers, 2008.

25. M. J. S. Dewar and D. M. Storch, "Development and Use of Quantum Molecular Models. 75. Comparative Tests of Theoretical Procedures for Studying Chemical Reactions," Journal of the American Chemical Society, vol. 107, no 13, pp. 3898-3902, 1985.

26. MOPAC2009 ${ }^{\mathrm{TM}}$, Available: http://openmopac.net/MOPAC2009.html. 